\title{
SF1126, a Pan-PI3K Inhibitor has Potent Pre-Clinical Activity in Aggressive B-Cell Non-Hodgkin Lymphomas by Inducing Cell Cycle Arrest and Apoptosis
}

\author{
Wenqing Qi ${ }^{1 *}$, Amy Stejskal ${ }^{1}$, Carla Morales ${ }^{1}$, Laurence S. Cooke ${ }^{1}$, Joseph R. Garlich ${ }^{1,2}$, Donald Durden $^{3}$ and Daruka Mahadevan ${ }^{\text {* }}$
}

${ }^{1}$ Arizona Cancer Center, Tucson, AZ85724, USA

${ }^{2}$ Signal RX Pharmaceuticals, Inc, USA

${ }^{3}$ University of California, San Diego, USA

\begin{abstract}
The PI3K pathway is activated in a variety of human tumors including B-cell Non Hodgkin Lymphoma (B-NHL). Targeting this pathway has been validated in solid tumors, leukemia and lymphomas. SF1126, a novel pan-PI3K inhibitor designed by conjugating RGD peptide to LY294002 facilitates clinical testing of this prodrug, suppresses growth and survival of multiple solid tumors in vitro and in vivo. In this study, we demonstrated SF1126 had potent activity in a panel of aggressive B-NHL cell lines. Cells treated with SF1126 exhibited decreased phosphorylation of Akt and GSK-3 $\beta$ confirming the mechanism of action of a PI3K inhibitor. Also, treatment of B-NHL cell lines with SF1126 induced apoptosis in a dose-dependent manner and inhibited cell proliferation with an $\mathrm{IC}_{50}<4 \mu \mathrm{M}$. However, the selective $1110 \delta$ inhibitor, CAL-101 was less potent in inducing apoptosis and inhibiting cell proliferation compared to SF1126. Moreover, SF1126 induced G1 cell cycle arrest significantly at low concentrations which contributed to suppression of cell proliferation and corroborated to a decrease in cyclin D1. Finally, rituximab enhanced apoptosis induced by SF1126 and CAL-101. Taken together, our findings provide for the first time that SF1126 inhibits the constitutively activated PI3K/Akt pathway in aggressive B-cell NHL cell lines with associated inhibition of cell cycle progression, cell proliferation and promotion of apoptosis. These findings suggest that SF1126 is a novel therapeutic strategy in aggressive B-cell NHL and warrants early phase clinical trial evaluation \pm rituximab.
\end{abstract}

Keywords: PI3K; B-cell non-Hodgkin lymphoma; SF1126; CAL101; Cell cycle; Apoptosis

\section{Introduction}

Aggressive B-cell Non-Hodgkin's Lymphoma (B-NHL) such as Diffuse Large B-cell Lymphoma (DLBCL), Mantle Cell Lymphoma (MCL), Burkitt's Lymphoma (BL) and Transformed Follicular Lymphoma (TFL) are incurable with current chemo-immunotherapy regimens including stem cell transplantation [1]. Therefore, the development of novel and effective treatments based on biologically validated targets is urgently needed for aggressive B-NHL. Clinical lymphoma research has focused on targeting signal transduction pathways and the tumor microenvironment in B-NHL particularly phosphoinositide 3-kinase (PI3K/Akt/mTORC), chronic B-cell receptor (BCR) activation (Syk and Btk) and protein kinase C [2-6]. The major goal is to incorporate these novel agents into existing antiB-NHL therapy by understanding their biologic roles and synthetic lethality.

PI3K binds to and is activated by several upstream receptors and non-receptor protein tyrosine kinases [7-10]. Once activated, PI3K phosphorylates its lipid substrate phosphatidylinositol 4,5-bisphosphate (PtdIns (4,5) P2) to PtdIns $(3,4,5)$ P3, a critical intra-cellular lipid second messenger. This process is opposed by the tumor suppressor PTEN (phosphatase and tension homolog) which is frequently deleted or mutated in human cancers [11] that results in constitutive PI3K activation. It in turn activates AKT, an important down-stream effector through interacting with PtdIns $(3,4,5)$ P3 via its $\mathrm{PH}$ domain which mediates cell proliferation, survival, cell cycle progression, apoptosis, angiogenesis and autophagy [12-14]. There are 3 classes of PI3K isoforms (I, II and III). Class I isoforms are subdivided into $1 \mathrm{~A}$ and $1 \mathrm{~B}$. Class $1 \mathrm{~A}$ is composed of $\mathrm{p} 110^{\alpha}, \mathrm{p} 110^{\beta}$ and $\mathrm{p} 110^{\delta}$ (catalytic domains), bound by p 85 , p50, or p55 (regulatory domains). Class $1 \mathrm{~B}$ consists of a single catalytic domain, $\mathrm{p} 110^{\gamma}$ bound by the regulatory domain $\mathrm{p} 101$. The relation between deregulated PI3K activity and cancer is well documented. Forced expression of PI3K was shown to be transforming in cell lines [15] and induced tumors [16] and angiogenesis in vivo [14]. It has also been shown that Akt is involved in malignant transformation [17]. PI3K activity has been linked to a variety of human tumors including breast cancer [18], lung cancer [19], melanomas [20], leukemia [21], colon and bladder carcinoma, glioblastoma, acute myeloid leukemia blasts [22,23], and non-Hodgkin's lymphoma [3,6]. Inhibition of the PI3K pathway is a promising approach for novel targeted therapeutic agents [24,25].

LY294002 is a pan inhibitor of all isoforms of PI3Kand has demonstrated anti-tumor and anti-angiogenic activities in vivo $[26,27]$. However, LY294002 compound is not a viable drug candidate due to insolubility and short half-life. Recently, SF1126, a novel RGD

*Corresponding authors: Daruka Mahadevan, Arizona Cancer Center, 1515, N Campbell Avenue, Tucson, AZ85724, USA, Tel: (520) 626-4331; Fax: (520) 6262225; E-mail: dmahadevan@azcc.arizona.edu

Wenqing Qi, Arizona Cancer Center, 1515 N Campbell Avenue, Tucson, AZ85724 USA, Tel: (520) 626-0190; Fax: (520) 626-2225; E-mail: wenqing@email.arizona edu, qiwq@yahoo.com

Received June 11, 2012; Accepted July 19, 2012; Published July 21, 2012

Citation: Qi W, Stejskal A, Morales C, Cooke LS, Garlich JR, et al. (2012) SF1126, a Pan-PI3K Inhibitor has Potent Pre-Clinical Activity in Aggressive B-Cell NonHodgkin Lymphomas by Inducing Cell Cycle Arrest and Apoptosis. J Cancer Sci Ther 4: 207-213. doi:10.4172/1948-5956.1000143

Copyright: @ 2012 Qi W, et al. This is an open-access article distributed under the terms of the Creative Commons Attribution License, which permits unrestricted use, distribution, and reproduction in any medium, provided the original author and source are credited. 
peptide conjugated LY294002 prodrug was developed by Semafore Pharmaceuticals [28] and is at the end of phase I clinical trials. Phase I study of the multi kinase prodrug SF1126 in solid tumors and B-cell malignancies [29], ASCO poster discussion, June 3-7, 2011. SF1126 is water soluble, has favorable pharmacokinetics, and is well tolerated in murine systems. It has been shown that SF1126 has anti-tumor activity in neuroblastoma, breast cancer cells [30], glioma cells and prostate cancer cells [28]. In this study, we demonstrate that SF1126 was superior to CAL-101 a PI3K delta-specific inhibitor in suppression of cell proliferation, induction of $\mathrm{G} 1 / \mathrm{S}$ arrest and promotion of apoptosis inaggressive B-cell NHL cell lines associated with inhibition of Akt and GSK-3 $\beta$ activity and down-regulation of cyclin D1. Further, the addition of rituximab to SF1126 or CAL-101 enhanced apoptosis compared to single agent activity. These results suggest that SF1126 + rituximab should be examined further as a potential therapeutic strategy for patients with aggressive B-cell NHL.

\section{Materials and Methods}

\section{Cells and reagents}

DLBC: SUDHL-4, TMD-8, TOLEDO, SUDHL-6, RL and DB; MCL: JeKo-1, Granta-519 and Granta-4 cell lines used in this study were from Drs. S. Grant (Virginia Commonwealth University, VA), L. Rimsza (University of Arizona, AZ) and C. Jordan (University of Rochester, NY) and maintained in RPMI 1640 medium (Mediatech, VA) supplemented with $10 \%$ fetal bovine serum, $2 \mathrm{mM}$ sodium pyruvate and 100 units $/ \mathrm{ml}$ penicillin/streptomycin at $37^{\circ} \mathrm{C}$ in a humidified atmosphere containing 5\% $\mathrm{CO}_{2}$. SF1126 was kindly provided by Semafore Pharmaceuticals (Indianapolis, IN). CAL-101 (p110 inhibitor) was purchased from Active Biochem (http://www. activebiochem.com). The compounds were dissolved at $10 \mathrm{mM}$ in $\mathrm{ddH}_{2} \mathrm{O}$ (for SF1126) and DMSO (for CAL-101) as a stock solution, and then further diluted to desired concentrations for in vitro experiments. Rituximab was a kind donation by the Arizona Cancer Center Clinic. Anti-phospho-Akt (Ser473), anti-Akt, anti-phospho-GSK-3 $\beta$ and anti$\beta$-actin antibodies were purchased from Cell Signaling Technology (Danvers, MA). Anti-PARP (H-250), anti-p53 and anti-CyclinD1 were from Santa Cruz Biotechnology (Santa Cruz, CA).

\section{Analysis of cell proliferation inhibition (MTS assay)}

Cells were seeded at 8,000 per well in 96-wellculture plates and allowed to grow for $24 \mathrm{hr}$ followed by the desired treatment with increasing concentrations of the indicated agents for 4 days. The studies were conducted in triplicates. Viable cell densities were determined using a Cell Titer 96 Cell Proliferation Assay (Promega, Madison, WI). The $\mathrm{IC}_{50}$ values were estimated by Calcusynsoftware (Biosoft, UK).

\section{Apoptosis assay}

Using Annexin V staining to detect apoptosis, treated cells were harvested and rinsed with cold PBS once. After centrifugation for 5 min, cells were resuspended in $500 \mu \mathrm{l}$ of $1 \times$ Annexin $\mathrm{V}$ binding buffer (BioVision, Annexin V-FITC Reagent Kit, Cat. \#1001-1000) and then added $5 \mu \mathrm{l}$ of Annexin V-FITC and $5 \mu \mathrm{l}$ of Propidium Iodide (BioVision, Annexin V-FITC Reagent Kit). After incubation for 5 min at room temperature in the dark, the samples were analyzed by flow cytometry.

\section{Cell cycle analysis}

Cells were treated with different concentrations of SF1126 and
CAL-101 for $48 \mathrm{hr}$ and then the cells were centrifuged at $1,500 \times \mathrm{g}$ for $5 \mathrm{~min}$ at $4^{\circ} \mathrm{C}$ and resuspended in PBS, fixed by drop wise addition of ice-cold ethanol (100\%) to a final concentration of $70 \%$, and incubated for $30 \mathrm{~min}$ on ice. Fixed cells were pelleted and treated with $100 \mu \mathrm{l}$ of RNase A $(0.2 \mathrm{mg} / \mathrm{ml}$ in PBS) for $5 \mathrm{~min}$ at room temperature, then

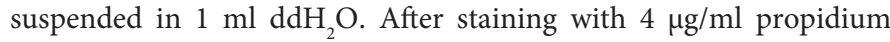
iodide, the DNA content was determined using a Becton Dickson flow cytometer and the cell cycle profile was analyzed by ModFit software. Cell aggregates were gated out of the analysis, based on the width of the propidium iodide fluorescence signal. Each profile was compiled from 10,000 gated events.

\section{Immunoblotting}

The cells were lysed in NP-40 lysis buffer containing $50 \mathrm{mM}$ Tris. $\mathrm{Cl}$ (pH 7.4), $0.15 \mathrm{M} \mathrm{NaCl}, 0.5 \%$ NP-40, 1 mM DTT, 50 mM Sodium Fluoride, and $2 \mu \mathrm{l} / \mathrm{ml}$ Protease inhibitor cocktail (Sigma, St. Louis, $\mathrm{MO}$ ). Protein concentrations were determined using the BioRad protein assay kit (Hercules, CA) and $50 \mu \mathrm{g}$ of protein was resolved by electrophoresis on a $10 \%$ SDS-PAGE gel. The proteins were then transferred onto a nitrocellulose membrane and nonspecific binding was blocked by incubating with $5 \%$ nonfat milk in TBST buffer $(0.01 \mathrm{M}$ Tris-Cl, $0.15 \mathrm{M} \mathrm{NaCl}, 0.5 \%$ Tween-20, $\mathrm{pH} 8.0$ ) at room temperature for $1 \mathrm{hr}$. The membrane was subjected to the indicated antibodies and the proteins were detected by a LI-COR Odyssey Infrared Imaging System.

\section{Statistical analysis}

All quantitative results are expressed as mean values \pm SD. Statistical tests were conducted with Graph Pad Prism version 5.0. $P$ values were 2 -tailed and considered significant if $P<0.05$.

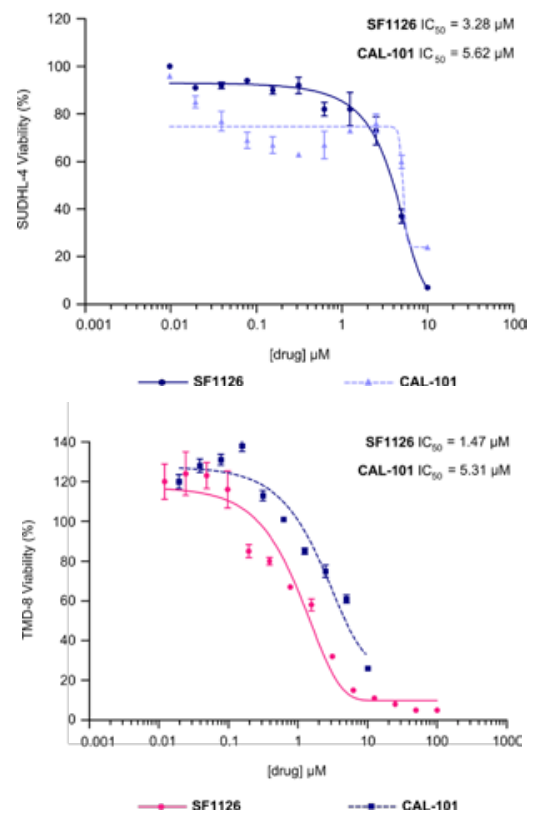

Figure 1: Antiproliferative activity of SF1126 and CAL-101 in aggressive B-NHL cell lines. SUDHL-4 and TMD-8 cells were exposed to varying concentrations of SF1126 and CAL-101 for 4 days. Cell viability was assessed by MTS analysis. Points are the means of triplicate determinations \pm SD. Inset: The $I_{50}$ s of SF1126 and CAL-101 were calculated in these two cell lines. A significant difference of IC50s between SF1126 and CAL-101 was determined by two-tailed t-test $(P=0.0063$ in SUDHL-4 and $P<0.0001$ in TMD-8). 


\section{Results}

SF1126 is superior to CAL-101 in suppressing cell proliferation in ABC and GCB DLBCL cell lines

PI3K is important for cancer cell survival and proliferation. SF1126, which is against all class I isoforms of PI3K, has been reported to suppress tumor growth in several solid types of cancers [28-30]. To examine whether SF1126 inhibits B-NHL cells, MTS assays were performed to evaluate the growth including SUDHL-4 and TMD8 which represents GCB and ABC DLBCL subtypes respectively. Consistent with previous studies, SF1126 effectively inhibited the growth of these two cell lines with $\mathrm{IC}_{50}$ values of $3.28 \mu \mathrm{M}$ and $1.47 \mu \mathrm{M}$ (Figure 1). CAL-101, a p110 $\delta$ selective PI3K inhibitor which has been shown to inhibit multiple myeloma [31], B-cell acute lymphoblastic leukemia [32] and chronic lymphocyte leukemia [33,34] was also used in this experiment as a positive control. Interestingly, the $\mathrm{IC}_{50}$ of CAL101 in SUDHL-4 and TMD-8 cells was higher than that of SF1126 (5.62 $\mu \mathrm{M}$ and $5.31 \mu \mathrm{M}$, respectively) (Figure 1). Statistical analysis indicated that the $\mathrm{IC}_{50} \mathrm{~s}$ were statistically significant difference between CAL101 and SF1126 in SUDHL-4 $(P=0.0063)$ and TMD-8 $(P<0.0001)$. Together, the data demonstrate that SF1126 is more potent against ABC- than GCB- DLBCL and is superior to CAL-101 against both types of DLBCL.

\section{SF1126 induces superior apoptosis to CAL-101 in DLBCL cell} lines

It is also known that apoptosis is induced when suppression of
PI3K pathway. To examine apoptosis, B-NHL cells were treated with varying doses of SF1126 and CAL-101, stained with Annexin V and PI and evaluated by flow cytometry assays. As expected, both of SF1126 and CAL-101 induced apoptosis in SUDHL-4 and TMD-8 B-NHL cells in a dose-dependent manner (Figure 2A and 2B). However, apoptosis was more prominent in both B-NHL cell lines treated with SF1126 versus CAL-101: $25 \%$ versus $12 \%$ in SUDHL-4 at $50 \mu \mathrm{M}$ and $20 \%$ versus $6 \%$ in TMD-8 at $20 \mu \mathrm{M}$. In addition, consistent with suppression of cell proliferation (Figure 1), SF1126 was more potent in inducing apoptosis in the ABC-type DLBCL (TMD-8) than GCB-type DLBCL (SUDHL-4):20\% versus $11 \%$ at $20 \mu \mathrm{M}$, respectively (Figure $2 \mathrm{~A}$ and 2B). These results were confirmed by demonstrating an increased level of cleaved PARP in treated B-NHL cells (Figure 2C). Furthermore, apoptosis was detected in a panel of additional B-cell NHL cell lines including mantle cell lymphoma treated with SF1126 (Figure 3A) with confirmatory PARP cleavage analysis (Figure 3B). B-NHL cells were treated with SF1126 at increasing doses $(5 \mu \mathrm{M}, 10 \mu \mathrm{M}, 20 \mu \mathrm{M}$, $40 \mu \mathrm{M}$ and $50 \mu \mathrm{M})$ and PARP cleavage was observed at a dose $>20$ $\mu \mathrm{M}$, suggesting apoptosis induction is dose-dependent (Figure $3 \mathrm{~B}$ ). In addition, apoptosis was induced as early as $8 \mathrm{hr}$ in B-NHL cells treated with SF1126 (Figure 3C).

\section{SF1126 inhibits cell cycle progression by down-regulating} cyclin D1 in aggressive B-NHL

Activation of the PI3K pathway regulates cell cycle progression [35,36]. SF1126 has been shown to induce G1 arrest in breast cancer cells [30]. To examine cell cycle progression in B-NHL, SUDHL-4 and
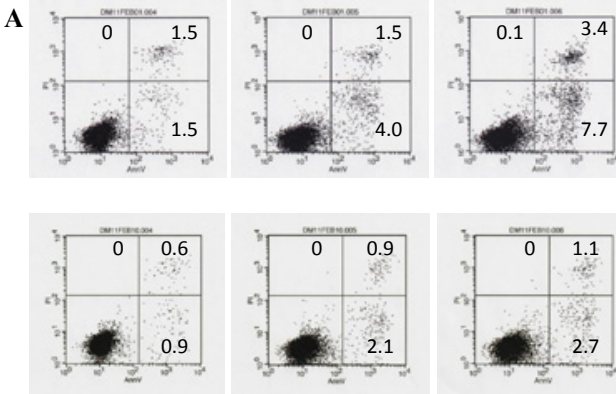

Control

$10 \mu \mathrm{M}$

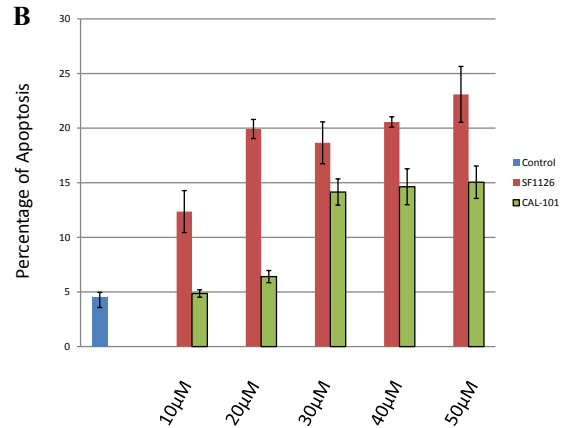

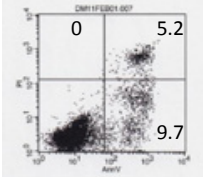
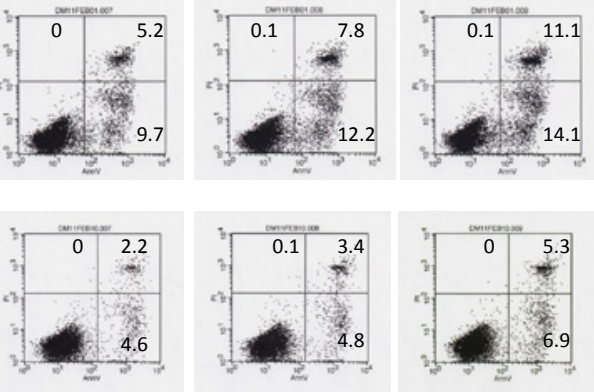

$30 \mu \mathrm{M}$

\section{옹}

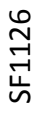

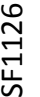

$50 \mu \mathrm{M}$

C

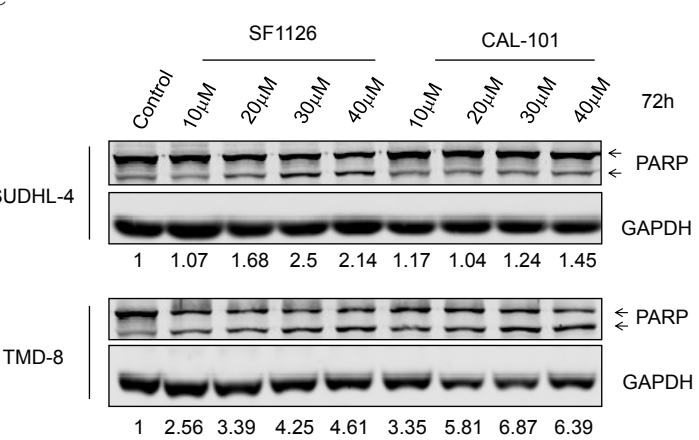

Figure 2: Apoptosis induction by SF1126 and CAL-101 inB-NHL cell lines. (A). SUDHL-4 cells were treated with SF1126 or CAL-101 at different doses [10 $\mu$ M, 20 $\mu \mathrm{M}, 30 \mu \mathrm{M}, 40 \mu \mathrm{M}$ and $50 \mu \mathrm{M}$ ] for 72-hr. Apoptosis was detected by flow cytometry based on propidium iodide (Y-axis) and annexin $V$ staining (X-axis). Percentages of apoptotic cells (lower right quadrant represents the early apoptotic population, upper right quadrant represents the late apoptotic population and upper left quadrant represents the necrotic population) are indicated. (B). TMD-8 cells were treated as above and apoptosis was analyzed by flow cytometry after staining of propidium iodide and annexin $\mathrm{V}$. The graph represents the mean percentage of apoptosis S.D. $(n=3)$. (C). SUDHL-4 and TMD-8 cells were treated with SF1126 and CAL-101 at $10 \mu \mathrm{M}, 20 \mu \mathrm{M}, 30 \mu \mathrm{M}$ and $40 \mu \mathrm{M}$ for $72 \mathrm{hr}$. Apoptosis was evaluated by immunoblotting to detect PARP cleavage with an anti-PARP antibody. GAPDH was used as a loading control. Numbers indicates density of cleaved PARP. 

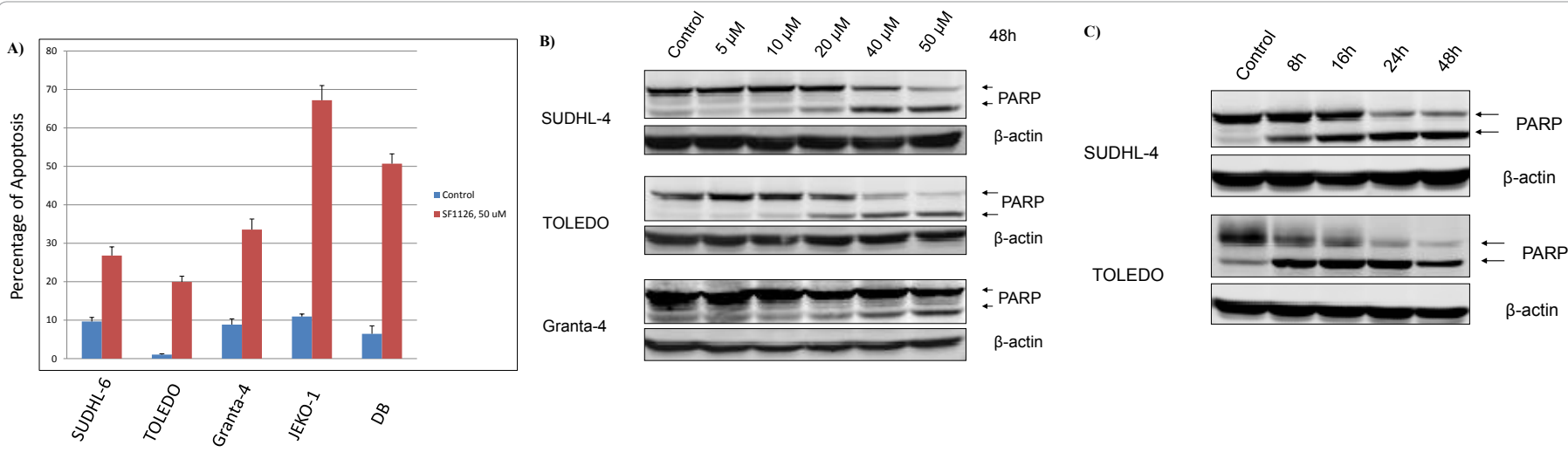

Figure 3: SF1126 induced apoptosis in additional aggressive B-NHL cell lines in a dose- dependent manner. (A). DLBCL cell lines: SUDHL-6, TOLEDO, DB and MCL cell lines: Granta-4 and JEKO-1 were treated with SF1126 at $50 \mu \mathrm{M}$ for $72 \mathrm{~h}$. Apoptosis was analyzed by flow cytometry. The graph represents the mean percentage of apoptosis \pm S.D. $(n=3)$. (B). SUDHL-4, TOLEDO and Granta-4 cells were treated with SF1126 at $5 \mu \mathrm{M}, 10 \mu \mathrm{M}, 20 \mu \mathrm{M}, 40 \mu \mathrm{M}$ and $50 \mu \mathrm{M}$ for $48 \mathrm{hr}$. PARP cleavage was detected by immunoblotting. (C). SUDHL-4 and TOLEDO cells were untreated or treated with SF1126 at $50 \mu \mathrm{M}$ at varying time points [8-hr, 16-hr, 24-hr and 48-hr]. PARP cleavage was determined using immunoblotting with an anti-PARP antibody. $\beta$-actin was used as a loading control.

A)
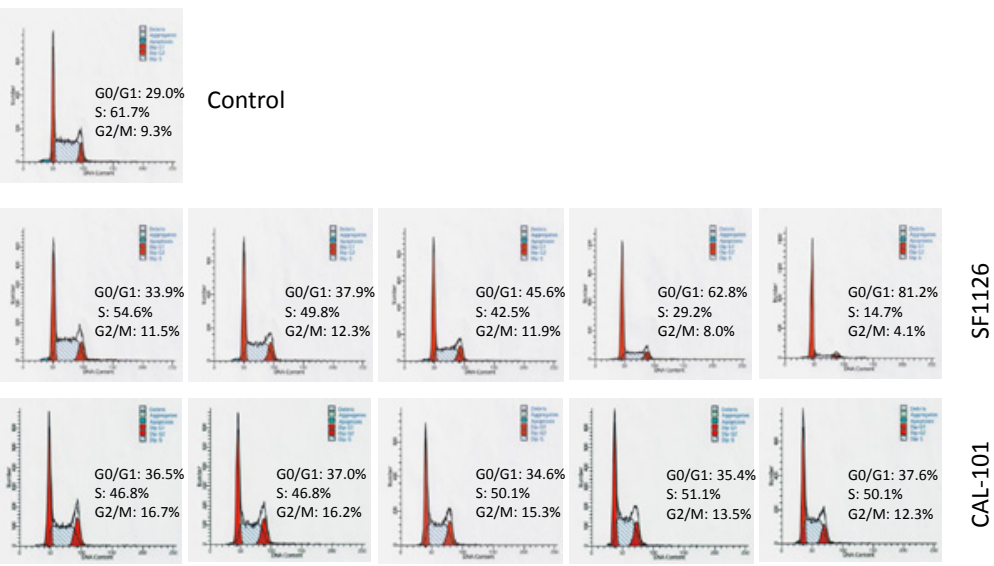

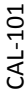

$0.5 \mu \mathrm{M}$

$1.0 \mu \mathrm{M}$

$2.0 \mu \mathrm{M}$

$5.0 \mu \mathrm{M}$

$10.0 \mu \mathrm{M}$

B)
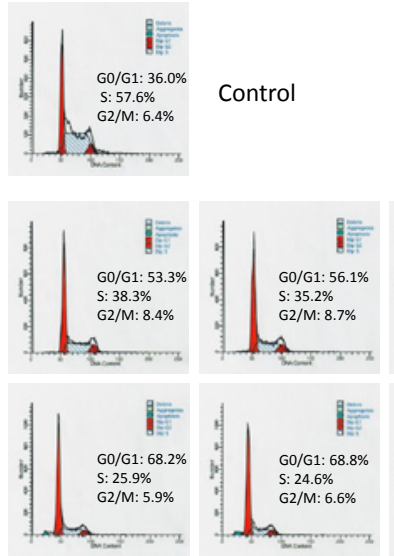

$0.5 \mu \mathrm{M}$

$1.0 \mu \mathrm{M}$
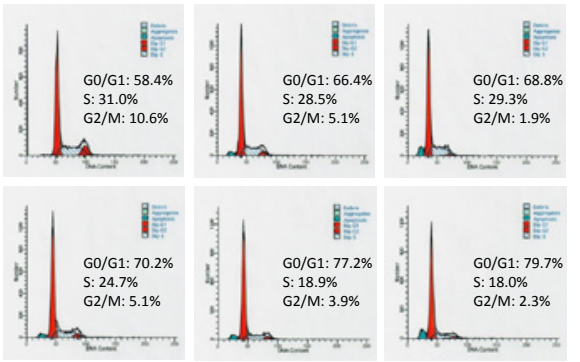

울

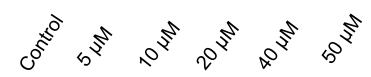

$48 \mathrm{~h}$

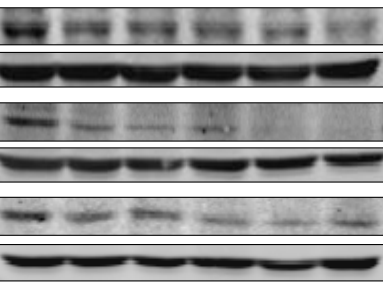

Cyclin D

$\beta$-actin

Cyclin D1

$\beta$-actin

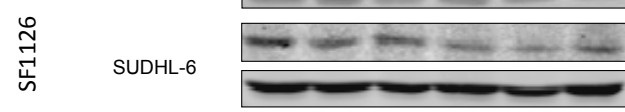

Cyclin D1

$\beta$-actin

Figure 4: SF1126 induced G1 arrest and decreased cyclin D1 in B-NHL cell lines. SUDHL-4 (A) and TMD-8 (B) cells were treated SF1126 or CAL-101 for 48 h at varying concentrations. Samples were harvested and stained with propidium iodide. DNA content was analyzed by flow cytometry. X-axis: DNA content, Y-axis: cell numbers. Percentages of G0/G1, S and G2/M phase cell populations were analyzed by ModFit software. (C). SUDHL-4, TOLEDO and SUDHL-6 cells were treated with SF1126 for $48 \mathrm{hr}$ at $5 \mu \mathrm{M}, 10 \mu \mathrm{M}, 20 \mu \mathrm{M}, 40 \mu \mathrm{M}$ and $50 \mu \mathrm{M}$. Cyclin D1 protein level was evaluated by immunoblotting. 
TMD-8 cells were treated with SF1126 or CAL-101 at $0.5 \mu \mathrm{M}, 1.0 \mu \mathrm{M}$, $2.0 \mu \mathrm{M}, 5.0 \mu \mathrm{M}$ and $10.0 \mu \mathrm{M}$ for $48 \mathrm{hr}$ and DNA content was evaluated using flow cytometry (Figure 4A and 4B). Treatment of B-NHL cells with SF1126 dramatically increased G0/G1 and decreased S phase populations in both DLBCL cell lines. However, CAL-101 had a similar effect only in the TMD-8 cell line (Figure $4 \mathrm{~A}$ and $4 \mathrm{~B}$ ), indicating a panPI3K inhibitor continues to be potent in different B-NHL subtypes. Very similar data were also observed in SUDHL-6, TOLEDO, RL, Granta-519 and Granta-4 cell lines (data not shown). Since cyclin D1 is a critical player in the G1/S cell cycle progression and is activated by the PI3K pathway [17], inhibition of PI3K by SF1126 led to a G1 arrest consistent with observed down-regulation of cyclin D1 at the protein level in B-NHL cells (Figure 4C).

\section{SF1126 inhibits PI3K/Akt/GSK-3 $\beta$ signaling in B-NHL cells}

Receptor tyrosine kinase or chronic B-cell receptor signaling leads to activation of the PI3K pathway whereby Akt is activated by phosphorylation at Thr308 by PDK1 and at Ser473 by PDK2. Subsequently, Akt promotes cell survival by inhibiting apoptosis by phosphorylating and inactivating several down-stream targets. Akt is also involved in cell cycle regulation by phosphorylating GSK-3 $\beta$ at Ser9 which mediates phosphorylation and degradation of cyclin D1 $[37,38]$. Hence, we examined the activity of Akt and GSK-3 $\beta$ when B-NHL cells were treated with SF1126. As expected, phosphorylation of Akt at Ser473 was significantly decreased with SF1126 even at 5 $\mu \mathrm{M}$. However, the total Akt protein level was unchanged upon SF1126 treatment, indicating that the decreased pSer473 was due to inhibition of phosphorylation and not to Akt protein degradation or translational down-regulation (Figure 5). Phospho-GSK-3 $\beta$ was also reduced dramatically by SF1126 in a dose-dependent manner (Figure 5). Hence, these data demonstrate that SF1126 effectively inhibits PI3K/Akt/GSK$3 \beta$ pathway in B-NHL cells.

\section{SF1126 plus rituximab enhances apoptosis in DLBCL cells}

It has been reported that rituximab $[\mathrm{R}]$ diminishes the constitutive activity of the PI3K/Akt signaling pathway and increases chemosensitization to drug-induced apoptosis [3]. Here we treated SUDHL-4 and TMD- 8 cells with $10 \mu \mathrm{M}$ of SF1126 alone, $20 \mu \mathrm{g} / \mathrm{ml}$ of R alone and

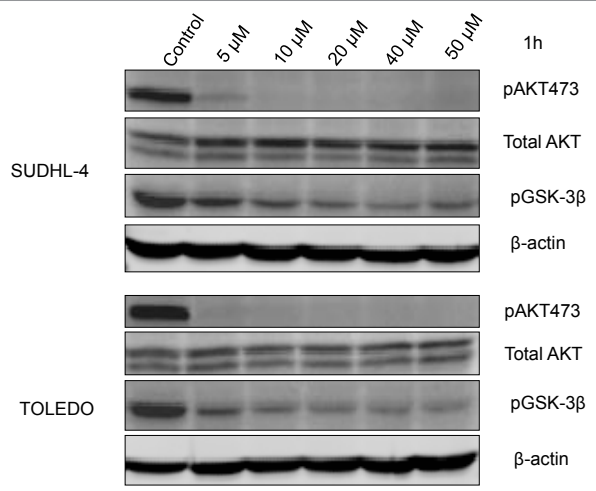

Figure 5: SF1126 potently inhibits phosphorylation of Akt and GSK-3 $\beta$. SUDHL-4 and TOLEDO cells were untreated or treated with SF1126 at $5 \mu \mathrm{M}$, $10 \mu \mathrm{M}, 20 \mu \mathrm{M}, 40 \mu \mathrm{M}$ and $50 \mu \mathrm{M}$ for 1-hr. Cells were collected for protein isolation. $50 \mu \mathrm{g}$ of total protein from each lysate was resolved by SDS-PAGE and immunoblotted with antibodies specific for pan-Akt, phosphorylated Akt (Ser473) and phosphorylated GSK-3 $\beta$ (Ser9). $\beta$-actin was used as a loading control.

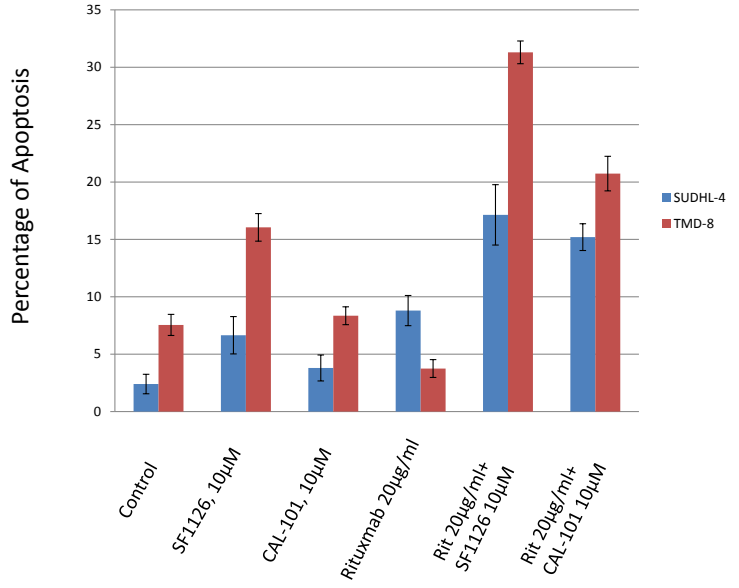

Figure 6: Rituximab enhances SF1126 induced apoptosis in aggressive B-NHL. SUDHL-4 and TMD-8 cells were untreated or treated with $10 \mu \mathrm{M}$ SF1126, $10 \mu \mathrm{M}$ CAL-101,20 $\mu \mathrm{g} / \mathrm{ml}$ of rituximab alone and combinations as indicated for $48 \mathrm{hr}$. Apoptosiswas evaluated by flow cytometry after Annixin $\mathrm{V}$ and $\mathrm{PI}$ staining. The graph represents the mean percentage of apoptosis \pm S.D. $(n=3)$.

the combination of SF1126 plus R for $48 \mathrm{hr}$. Apoptosis was evaluated and the results clearly show R plus SF1126 induced more apoptosis than R or SF1126 alone (Figure 6). Rituximab also enhanced apoptosis in the cells treated with CAL-101, suggesting rituximab increases the anti-tumor activity of PI3K inhibitors in B-cell NHL cells.

\section{Discussion}

Most aggressive B-cell non-Hodgkin lymphomas (B-NHL) are not curable with current chemo-immunotherapy combinations [1]. The PI3K/Akt/mTORC signaling pathway is frequently deregulated in B-NHL [3,6], promoting the evaluation of novel small molecule inhibitors as an alternative treatment strategy. Indeed, disruption of mTORC1, an important down-stream mediator of PI3K/Akt, with rapalogs is now accepted as a therapeutic conceptin relapsed/refractory mantle cell lymphoma [6]. In this study, we demonstrate that SF1126, a novel pan-PI3Kprodrug small molecule inhibitor, potently suppresses cell proliferation, induces G1 cell cycle arrest by inhibiting cyclin D1 protein level, and promotes apoptosis with suppression of Akt and GSK-3 $\beta$ activity in a panel of aggressive B-NHL cell lines. SF1126 has been shown to have potent anti-tumor activity in glioma, prostate cancer [28], recurrent neuroblastoma [29] and breast cancer [30]. A phase I trial evaluated SF1126 in patients with advanced solid tumors and B-cell lymphoproliferative diseases including CLL [D. Mahadevan et al. Phase I study of the multikinaseprodrug SF1126 in solid tumors and B-cell malignancies, ASCO poster discussion, June 3-7, 2011]. However, few studies have been done to evaluate SF1126 activity in aggressive B-NHL. Our results here support the inhibition of PI3K by SF1126 may represent a novel therapeutic strategy that warrants clinical trial evaluation in aggressive B-NHL.

CAL-101, a potent and selective p110 $\delta$ inhibitor, has been extensively assessed and shows significant pre-clinical activity in multiple myeloma [31], chronic lymphocytic leukemia [34] and immature or mature B-cell malignancies [32]. Compared with SF1126, CAL-101 is less effective in suppressing cell proliferation and promoting apoptosis in B-NHL. The most likely explanation is redundancy leading 
to resistance as other PI3K class I isoforms such as p110a, p110 $\beta$ and p110 $\gamma$ exist in an activated form these subtypes of B-NHL. In fact, all of the PI3K class I isoforms are expressed and active in a variety of ABCtype DLBCL cell lines including TMD-8 [5]. Additionally SF1126 is also known to inhibit mTORC1 and 2, PIM-1 and DNA-PK which are also therapeutic targets in B-NHL [28]. Moreover, PI3K/Akt/mTORC is frequently activated in all subtypes of B-NHL including DLBCL [39], MCL [40] and follicular lymphoma [41,42]. Hence, a pan-PI3K inhibitor is likely to be more active than an isoform selective inhibitor for the treatment of B-NHL.

SF1126 inhibits cell proliferation at low concentrations $\left(\mathrm{IC}_{50}<3.5\right.$ $\mu \mathrm{M}$ ) (Figure 1). However, in cell culture $>10 \mu \mathrm{M}$ of SF1126 is required to induce apoptosis (Figure 2). In the phase I trial of SF1126 a maximum tolerated dose was not reached based on toxicity with the maximum administered dose being $1110 \mathrm{mg} / \mathrm{m}^{2}$ administered intravenously twice weekly three days apart. The pharmacokinetics showed that serum levels of $25 \mu \mathrm{M}$ were readily achieved. (D. Mahadevan et al. [1] Phase I study of the multikinaseprodrug SF1126 in solid tumors and B-cell malignancies, ASCO poster discussion, June 3-7, 2011). Thus, G1 cell cycle arrest may contribute more to suppression of cell proliferation by SF1126 as this is achieved at low concentrations (Figure 4). Cyclin D1, is an oncogene that regulates the G1-S cell cycle transition in B-NHL, particularly in MCL where it is over-expressed due to the $t(11 ; 14)$ (q13;q32) chromosomal translocation. Pre-clinical studies have shown frequent activation of MTORC1 in MCL patients and cell lines and inhibition with rapalogs leads to decreased cyclin D1 expression [40]. Also cyclin D1 is regulated by glycogen synthase kinase $3 \beta$ (GSK-3 $\beta$ ) as the latter phosphorylates cyclin D1 at Thr286, leading to ubiquitinmediated proteolytic degradation in the cytoplasm [37]. The activity of GSK-3 $\beta$ is inhibited by Akt-dependent phosphorylation and thus Akt mediated GSK-3 $\beta$ inhibition stabilizes cyclin D1. Over-expression of constitutively active Akt extends the half-life of cyclin D1 protein whereas treatment with the PI3K inhibitor (e.g. Wortmannin) accelerated its degradation [37]. Consistent with these findings, SF1126 activates GSK-3 $\beta$ through inhibition of PI3K/Akt and decreases cyclin D1 protein in B-NHL (Figure 5).

In conclusion, our findings indicate that inhibition of the PI3K/ Akt/mTORC pathway is an excellent therapeutic strategy for aggressive B-NHL. SF1126, a pan-PI3K inhibitor that also inhibits mTORC1 and 2 is superior to CAL-101 a PI3K delta-specific inhibitor in reducing tumor cell proliferation, enhancing apoptosis and induction of G1 cell cycle arrest in aggressive B-NHL. PI3K pathway inhibition by SF1126 was confirmed by decreased phosphorylation of Akt and GSK-3 $\beta$ with associated decrease in cyclin D1. Finally combining SF1126 with rituximab increased apoptosis and may be a synthetic lethal interaction (Figure 6). These results suggest that SF1126 should be evaluated in combination with rituximab in early therapeutic trials in aggressive B-cell NHL.

\section{Acknowledgements}

We wish to thank the Lymphoma SPORE (P50 CA130805501A1) and Semafore Pharmaceuticals for funding this project.

\section{References}

1. Mahadevan D, Fisher RI (2011) Novel therapeutics for aggressive nonHodgkin's lymphoma. J Clin Oncol 29: 1876-1884.

2. Witzig TE, Gupta M (2010) Signal transduction inhibitor therapy for lymphoma. Hematology Am Soc Hematol Educ Program 2010: 265-270.
3. Suzuki E, Umezawa K, Bonavida B (2007) Rituximab inhibits the constitutively activated PI3K-Akt pathway in B-NHL cell lines: involvement in chemosensitization to drug-induced apoptosis. Oncogene 26: 6184-6193.

4. Garcia-Martinez JM, Wullschleger S, Preston G, Guichard S, Fleming S, et al. (2011) Effect of PI3K- and mTOR-specific inhibitors on spontaneous B-cel follicular lymphomas in PTEN/LKB1-deficient mice. Br J Cancer 104: 11161125.

5. Kloo B, Nagel D, Pfeifer M, Grau M, Duwel M, et al. (2011) Critical role of PI3K signaling for NF-kappaB-dependent survival in a subset of activated B-cell-like diffuse large B-cell lymphoma cells. Proc Natl Acad Sci U S A 108: 272-277.

6. Schatz JH (2011) Targeting the PI3K/AKT/mTOR pathway in non-Hodgkin's Lymphoma: results, biology, and development strategies. Curr Oncol Rep 13: 398-406

7. Chan TO, Rittenhouse SE, Tsichlis PN (1999) AKT/PKB and other D3 phosphoinositide-regulated kinases: kinase activation by phosphoinositidedependent phosphorylation. Annu Rev Biochem 68: 965-1014.

8. Chen HC, Guan JL (1994) Association of focal adhesion kinase with its potential substrate phosphatidylinositol 3-kinase. Proc Natl Acad Sci U S A 91 10148-10152.

9. Izuhara K, Feldman RA, Greer P, Harada N (1996) Interleukin-4 induces association of the $\mathrm{c}$-fes proto-oncogene product with phosphatidylinositol-3 kinase. Blood 88: 3910-3918.

10. Karnitz LM, Sutor SL, Abraham RT (1994) The Src-family kinase, Fyn, regulates the activation of phosphatidylinositol 3-kinase in an interleukin 2-responsive $T$ cell line. J Exp Med 179: 1799-1808.

11. Leslie NR, Downes CP (2002) PTEN: The down side of PI 3-kinase signalling Cell Signal 14: 285-295.

12. Duronio V, Scheid MP, Ettinger S (1998) Downstream signalling events regulated by phosphatidylinositol 3-kinase activity. Cell Signal 10: 233-239.

13. Kandel ES, Hay N (1999) The regulation and activities of the multifunctional serine/threonine kinase Akt/PKB. Exp Cell Res 253: 210-229.

14. Jiang BH, Zheng JZ, Aoki M, Vogt PK (2000) Phosphatidylinositol 3-kinase signaling mediates angiogenesis and expression of vascular endothelial growth factor in endothelial cells. Proc Natl Acad Sci U S A 97: 1749-1753.

15. Kang S, Denley A, Vanhaesebroeck B, Vogt PK (2006) Oncogenic transformation induced by the p110beta, -gamma, and -delta isoforms of class I phosphoinositide 3-kinase. Proc Natl Acad Sci U S A 103: 1289-1294.

16. Chang HW, Aoki M, Fruman D, Auger KR, Bellacosa A, et al. (1997) Transformation of chicken cells by the gene encoding the catalytic subunit of $\mathrm{P}$ 3-kinase. Science 276: 1848-1850.

17. Chang F, Lee JT, Navolanic PM, Steelman LS, Shelton JG, et al. (2003) Involvement of PI3K/Akt pathway in cell cycle progression, apoptosis, and neoplastic transformation: a target for cancer chemotherapy. Leukemia 17 : 590-603.

18. Fry MJ (2001) Phosphoinositide 3-kinase signalling in breast cancer: how big a role might it play? Breast Cancer Res 3: 304-312.

19. Lin X, Bohle AS, Dohrmann P, Leuschner I, Schulz A, et al. (2001) Overexpression of phosphatidylinositol 3-kinase in human lung cancer. Langenbecks Arch Surg 386: 293-301.

20. Krasilnikov M, Adler V, Fuchs SY, Dong Z, Haimovitz-Friedman A, et al. (1999) Contribution of phosphatidylinositol 3-kinase to radiation resistance in human melanoma cells. Mol Carcinog 24: 64-69.

21. Martinez-Lorenzo MJ, Anel A, Monleon I, Sierra JJ, Pineiro A, et al. (2000) Tyrosine phosphorylation of the p85 subunit of phosphatidylinositol 3-kinase correlates with high proliferation rates in sublines derived from the Jurkat leukemia. Int J Biochem Cell Biol 32: 435-445.

22. Chen JS, Zhou LJ, Entin-Meer M, Yang X, Donker M, et al. (2008) Characterization of structurally distinct, isoform-selective phosphoinositide 3'-kinase inhibitors in combination with radiation in the treatment of glioblastoma. Mol Cancer Ther 7: 841-850.

23. Hafner C, Lopez-Knowles E, Luis NM, Toll A, Baselga E, et al. (2007) Oncogenic 
Citation: Qi W, Stejskal A, Morales C, Cooke LS, Garlich JR, et al. (2012) SF1126, a Pan-PI3K Inhibitor has Potent Pre-Clinical Activity in Aggressive B-Cell Non-Hodgkin Lymphomas by Inducing Cell Cycle Arrest and Apoptosis. J Cancer Sci Ther 4: 207-213. doi:10.4172/1948-5956.1000143

PIK3CA mutations occur in epidermal nevi and seborrheic keratoses with a characteristic mutation pattern. Proc Natl Acad Sci U S A 104: 13450-13454.

24. Lin TS (2010) New agents in chronic lymphocytic leukemia. Curr Hematol Malig Rep 5: 29-34.

25. Coughlin CM, Johnston DS, Strahs A, Burczynski ME, Bacus S, et al. (2010) Approaches and limitations of phosphatidylinositol-3-kinase pathway activation status as a predictive biomarker in the clinical development of targeted therapy. Breast Cancer Res Treat 124: 1-11.

26. Hu L, Zaloudek C, Mills GB, Gray J, Jaffe RB (2000) In vivo and in vitro ovarian carcinoma growth inhibition by a phosphatidylinositol 3-kinase inhibitor (LY294002). Clin Cancer Res 6: 880-886.

27. Su JD, Mayo LD, Donner DB, Durden DL (2003) PTEN and phosphatidylinositol 3'-kinase inhibitors up-regulate p53 and block tumor-induced angiogenesis: evidence for an effect on the tumor and endothelial compartment. Cancer Res 63: 3585-3592.

28. Garlich JR, De P, Dey N, Su JD, Peng X, et al. (2008) A vascular targeted pan phosphoinositide 3-kinase inhibitor prodrug, SF1126, with antitumor and antiangiogenic activity. Cancer Res 68: 206-215.

29. Peirce SK, Findley HW, Prince C, Dasgupta A, Cooper T, et al. (2011) The PI-3 kinase-Akt-MDM2-survivin signaling axis in high-risk neuroblastoma: a target for PI-3 kinase inhibitor intervention. Cancer Chemother Pharmaco 68: 325335

30. Ozbay T, Durden DL, Liu T, O’Regan RM, Nahta R (2010) In vitro evaluation of pan-PI3-kinase inhibitor SF1126 in trastuzumab-sensitive and trastuzumabresistant HER2-over-expressing breast cancer cells. Cancer Chemother Pharmacol 65: 697-706.

31. Ikeda H, Hideshima T, Fulciniti M, Perrone G, Miura N, et al. (2010) PI3K p110 \{delta\} is a novel therapeutic target in multiple myeloma. Blood 116: 14601468.

32. Lannutti BJ, Meadows SA, Herman SE, Kashishian A, Steiner B, et al. (2011) CAL-101, a p110delta selective phosphatidylinositol-3-kinase inhibitor for the treatment of B-cell malignancies, inhibits PI3K signaling and cellular viability. Blood 117: 591-594.
33. Herman SE, Lapalombella R, Gordon AL, Ramanunni A, Blum KA, et al. (2011) The role of phosphatidylinositol 3-kinase-delta in the immunomodulatory effects of lenalidomide in chronic lymphocytic leukemia. Blood 117: 4323-4327.

34. Herman SE, Gordon AL, Wagner AJ, Heerema NA, Zhao W, et al. (2010) Phosphatidylinositol 3-kinase-delta inhibitor CAL-101 shows promising preclinical activity in chronic lymphocytic leukemia by antagonizing intrinsic and extrinsic cellular survival signals. Blood 116: 2078-2088.

35. Liang J, Slingerland JM (2003) Multiple roles of the PI3K/PKB (Akt) pathway in cell cycle progression. Cell Cycle 2: 339-345.

36. Gao N, Flynn DC, Zhang Z, Zhong XS, Walker V, et al. (2004) G1 cell cycle progression and the expression of $\mathrm{G} 1$ cyclins are regulated by PI3K/AKT/ mTOR/p70S6K1 signaling in human ovarian cancer cells. Am J Physiol Cell Physiol 287: C281-C291.

37. Diehl JA, Cheng M, Roussel MF, Sherr CJ (1998) Glycogen synthase kinase 3beta regulates cyclin D1 proteolysis and subcellular localization. Genes Dev 12: 3499-3511.

38. Chen XL, Ren KH, He HW, Shao RG (2008) Involvement of PI3K/AKT/ GSK3beta pathway in tetrandrine-induced G1 arrest and apoptosis. Cancer Biol Ther 7: 1073-1078.

39. Uddin S, Hussain AR, Siraj AK, Manogaran PS, Al-Jomah NA, et al. (2006 Role of phosphatidylinositol 3'-kinase/AKT pathway in diffuse large B-cell lymphoma survival. Blood 108: 4178-4186.

40. Peponi E, Drakos E, Reyes G, Leventaki V, Rassidakis GZ, et al. (2006) Activation of mammalian target of rapamycin signaling promotes cell cycle progression and protects cells from apoptosis in mantle cell lymphoma. Am J Pathol 169: 2171-2180

41. Gupta M, Dillon SR, Ziesmer SC, Feldman AL, Witzig TE, et al. (2009) A proliferation-inducing ligand mediates follicular lymphoma B-cell proliferation and cyclin D1 expression through phosphatidylinositol 3-kinase-regulated mammalian target of rapamycin activation. Blood 113: 5206-5216.

42. Leseux L, Hamdi SM, Al Saati T, Capilla F, Recher C, et al. (2006) Syk dependent mTOR activation in follicular lymphoma cells. Blood 108: 41564162. 